\title{
Perfil nutricional de pacientes HIV/Aids hospitalizados
}

\section{Nutritional profile of hospitalized HIV/AIDS patients}

El perfil nutricional de los pacientes con VIH/SIDA hospitalizados

Camila Nunes de Souza ${ }^{1}$

Oswaldo Lorenço Brito Costa ${ }^{2}$

Fabiane La Flor Ziegler Sanches ${ }^{3}$

Rita de Cássia Avellaneda Guimarães ${ }^{4}$

${ }^{1}$ Especialista pelo Programa de Residência Multiprofissional em Atenção ao Paciente Crítico. Tem experiência na área de Nutrição Clínica e Hospitalar. Universidade Federal de Mato Grosso do Sul (UFMS). E-mail: nutricamilanunes@hotmail.com.

${ }^{2}$ Graduando em medicina pela Universidade Federal de Mato Grosso do Sul (UFMS).E-mail: olbc27@gmail.com

${ }^{3}$ Mestrado e doutorado em Alimentos e Nutrição pela Universidade Estadual de Campinas (UNICAMP). Especialização em Terapia Nutricional e Nutrição Clínica pelo Ganep Nutrição Humana. Graduação em Nutrição pelo Centro Universitário

Franciscano (UNIFRA). Graduação em Farmácia pela Universidade Federal de

Santa Maria (UFSM). Professora Adjunta da Universidade Federal do Mato Grosso do Sul (UFMS). Coordenação do Curso de Nutrição. Atua principalmente nos seguintes temas: alimentos funcionais, proteínas do soro de leite, frutos do

Cerrado e pesquisa clínica e experimental. E-mail: fabianelaflor@gmail.com

${ }^{4}$ Doutorado pelo Programa de Pós-Graduação em Saúde e Desenvolvimento na Região Centro-Oeste pela Universidade Federal de Mato Grosso do Sul (UFMS), sendo bolsista CAPES, atuando na linha de pesquisa, Metabolismo e Nutrição.

Graduação em Nutrição e mestrado em Biotecnologia pela Universidade Católica Dom Bosco. Professora Adjunta Nível III do curso de Nutrição na UFMS e docente do quadro permanente do Programa de Pós Graduação em Saúde e Desenvolvimento na Região Centro-Oeste da Faculdade de Medicina (FAMED) da UFMS. Pesquisa a Biodiversidade do Cerrado e Pantanal, trabalhando com frutos nativos e plantas desta Região. E-mail: rita.guimaraes@ufms.br 
Resumo: A Síndrome da Imunodeficiência Adquirida (SIDA) ou Aids é geralmente acompanhada de ingestão inadequada e balanço energético negativo. O objetivo desta pesquisa foi realizar o acompanhamento nutricional de pacientes com HIV/Aids hospitalizados, diagnosticando seu estado nutricional, desde a sua admissão até o desfecho hospitalar, considerando os aspectos sociais, clínicos, físicos, antropométricos, laboratoriais e consumo alimentar. Verificou- se que metade dos indivíduos sabiam do diagnóstico de HIV há pelo menos um ano e, destes, 53,6\% não realizavam tratamento regular com TARV. Nas comorbidades, destacaram-se neurotoxoplasmose e pneumocistose. Na avaliação nutricional: $87,5 \%$ dos indivíduos apresentavam-se hipoalbuminêmicos e com elevados níveis de PCR. O IMC, adequação da CB e adequação de peso indicaram desnutrição. $A$ oferta por via oral e de qualidade hiperproteica prevaleceu durante o acompanhamento. Os resultados apontaram que a situação de desnutrição é presente no ambiente hospitalar e está relacionada fortemente à situação nutricional.

Palavras-chave: Síndrome da Imunodeficiência Adquirida; cuidado nutricional; acompanhamento nutricional.

\begin{abstract}
Acquired Immunodeficiency Syndrome (AIDS) or HIV is usually accompanied by inadequate intake and a negative energy balance. The objective of this study was to carry out the nutritional monitoring of patients hospitalized with HIV/Aids, diagnosing their nutritional status, from admission to hospital outcome, considering social, clinical, physical, anthropometric, laboratory and food consumption aspects. It was verified that a half of the individuals knew the diagnosis of HIV for at least one year and of these, 53.6\% did not have regular HAART treatment. In the comorbidities, neurotoxoplasmosis and pneumocystosis were highlighted. In the nutritional evaluation: $87.5 \%$ of the subjects were with hypoalbuminemic and with high CRP levels. BMI, CB adequacy and weight adequacy indicated malnutrition. The oral supply and hyperprotection quality prevailed during followup. The results showed that malnutrition is present in the hospital environment, and the nutritional situation is strongly related.
\end{abstract}

Keywords: Acquired Immunodeficiency Syndrome; nutritional care; nutritional monitoring.

Resumen: El Síndrome de Inmunodeficiencia Adquirida (SIDA) o el HIV es generalmente acompañado de una ingestión inadecuada y un balance energético negativo. El objetivo de esta investigación fue realizar el seguimiento nutricional de pacientes con HIV/SIDA hospitalizados, diagnosticando su estado nutricional, desde su admisión hasta el desenlace hospitalario, considerando los aspectos sociales, clínicos, físicos, antropométricos, de laboratorio y consumo alimentario. Se verificó que la mitad de los individuos sabían del diagnóstico del VIH durante al menos un año y de éstos, el 53,6\% no realizaba tratamiento regular con TARV. En las comorbilidades, se destacaron neurotoxoplasmosis y neumocistosis. En la evaluación nutricional: $87,5 \%$ de los individuos se presentaban hipoalbuminemicos y con altos niveles de PCR. El IMC, adecuación de la CB y adecuación de peso indicaron desnutrición. La oferta por vía oral y de calidad hiperproteica prevaleció durante el seguimiento. Los resultados apuntaron que la situación de desnutrición está presente en el ambiente hospitalario, y está relacionada fuertemente la situación nutricional.

Palabras clave: Síndrome de Inmunodeficiencia Adquirida; la atención nutricional; asesoramiento nutricional. 


\section{INTRODUÇÃO}

A Síndrome da Imunodeficiência Adquirida (SIDA) ou Acquired Immnunodeficiency Syndrome (Aids) é uma doença infectocontagiosa causada pelo vírus Human Immunodeficiency Virus (HIV). É chamada de Aids quando há o desenvolvimento de doenças oportunistas ou contagem de linfócitos T Helper (L Th) no sangue inferior a 200 células $/ \mathrm{mm}^{3} \mathrm{~A}$ infecção pelo vírus HIV+ comumente acontece pela contaminação por intercurso anal e vaginal. No entanto os contatos com sangue, sêmen, fluido pré-seminal e outros fluidos corporais que contenham sangue são altamente contaminantes e predispõem o indivíduo ao risco elevado de contrair a doença.

Esses indivíduos são acometidos na grande maioria, pela perda de peso, caracterizada pela redução da composição corporal que pode acelerar a progressão da doença e piora o seu estado funcional, sendo a desnutrição considerada uma das maiores complicações no HIV+. Com isso, a avaliação nutricional tem como objetivo evitar ou reverter a desnutrição, fornecer aporte adequado de nutrientes, minimizar os efeitos colaterais de terapia antirretroviral, diminuir os sintomas de má-absorção, preservar a massa magra e promover boa qualidade de vida. Para se obter um diagnóstico fidedigno, é essencial a avaliação antropométrica (circunferências e dobras cutâneas). Desnutrição, imunodeficiência e infecção compõem uma tríade que deve ser evitada.

Todavia o consumo alimentar determinado por ingestão oral diminuída é identificado como a causa mais comum de perda de peso e anemia. A baixa ingestão oral pode ser atribuída a distúrbios bucais e esofágicos, como candidíase, herpes ou úlceras aftosas. Quando a alimentação oral é insuficiente, a nutrição enteral pode ser utilizada como um adjunto ou em casos extremos utiliza-se também a nutrição parenteral. Para tanto, é necessário que a conduta nutricional programada, possa ser aplicada.

Quanto à nutrição enteral, os fatores que impedem o adequado aporte nutricional incluem os relacionados à intolerância da dieta, os associados às práticas de rotina de enfermagem (manipulação do paciente, administração de medicamentos, dentre outros) e demais rotinas (procedimentos clínicos e laboratoriais). Nesses casos, o cuidado nutricional e o reconhecimento 
desses fatores permitem a adoção de medidas que torne adequado o aporte calórico-proteico para esses pacientes.

O objetivo desta pesquisa foi realizar o acompanhamento nutricional dos pacientes com HIV/Aids hospitalizados, diagnosticando seu estado nutricional, desde a sua admissão até o desfecho hospitalar, considerando os aspectos norteadores da doença: sociais, clínicos, físicos, antropométricos, laboratoriais e consumo alimentar.

\section{METODOLOGIA}

\subsection{Delineamento do estudo e aspectos éticos}

Trata-se de um estudo descritivo quantitativo de acompanhamento durante o período de internação dos pacientes hospitalizados com diagnóstico de infecção pelo HIV, internados no Pronto Atendimento Médico (PAM) e na clínica de Doenças Infecto Parasitárias (DIP) do hospital Universitário Maria Aparecida Pedrossian (HUMAP) na cidade de Campo Grande, Mato Grosso do Sul, sendo este, referência para internação e tratamento de doenças infecciosas. Este estudo deu início após aprovação do Comitê de Ética em Pesquisa com Seres Humanos da Universidade Federal do Mato Grosso do Sul (CEP/UFMS) n. 1345.893, nos períodos de março a junho de 2016.

\subsection{Perfil dos pacientes}

Participaram deste estudo 40 indivíduos admitidos com diagnóstico de HIV anteriormente ou descoberto até 3 dias após internação; de ambos os sexos, com faixa etária entre 18 a 59 anos, os quais se enquadravam na pesquisa, com no mínimo duas avaliações nutricionais subsequentes (para comparação). Foram excluídos deste estudo as gestantes, pacientes em terapia nutricional parenteral e os pacientes que apresentaram alteração do estado mental sem o acompanhamento de um responsável legal. A participação deles foi certificada após assinarem o Termo de Consentimento Livre e Esclarecido (TCLE). 


\subsection{Coleta de dados}

A coleta dos dados deu-se através de um formulário padronizado, estruturado e elaborado pela pesquisadora. O Formulário era subdivido em duas partes (ficha de Anamnese de admissão e ficha de acompanhamento nutricional).

A ficha anamnese de admissão era preenchida na primeira avaliação e contemplava informações sociais, história de hábito e/ou alteração nos aspectos nutricionais e do estado nutricional, exame físico, sintomas gastrointestinais, comorbidades, avaliação antropométrica, exames laboratoriais e dados clínicos específicos do HIV, informações relevantes relacionados a dieta hospitalar como: via de administração da dieta, oferta nutricional e qualidade da dieta (normocalórica ou hipercalórica, normoproteica ou hiperproteica).

Após era preenchida apenas a ficha de acompanhamento nutricional, uma vez por semana, e utilizada durante todo o período de hospitalização do paciente, até o momento de desfecho clínico (alta hospitalar ou óbito). Nesta ficha, encontravam-se informações referentes à avaliação do estado nutricional considerando as seguintes variáveis: exame físico, antropometria, exames laboratoriais e avaliação de consumo alimentar, para acompanhamento.

\subsection{Acompanhamento nutricional}

O acompanhamento nutricional ocorreu uma vez por semana, durante a internação hospitalar. Vale ressaltar que não houve intervenção nutricional (conduta dietética/dietoterápica) aos indivíduos. Abaixo estão descritas as especificidades das variáveis avaliadas durante o acompanhamento nutricional do paciente.

\subsubsection{Avaliação clínica}

Para análise da situação imunológica e virológica, foram considerados resultados da contagem de linfócitos T CD4 e carga viral existentes nos prontuários. Foi considerado o resultado mais próximo da data de coleta de dados e analisado apenas na admissão. A contagem de CD4 foi estrati- 
ficada usando $200 \mathrm{cel} / \mathrm{mm}^{3}$ como ponto de corte, uma vez que CD4 < 200 $\mathrm{cel} / \mathrm{mm}^{3}$ um dos critérios para diagnosticar AIDS em pacientes com HIV (GARCIA; QUINTAES; MERHI, 2000). Também foram analisadas creatinina, ureia, proteínas totais e albumina sérica, então avaliados semanalmente. Os dados referentes aos exames laboratoriais foram obtidos por meio de resultados contínuos no prontuário e no sistema eletrônico do hospital- SIL (Sistema de Informações Laboratoriais), considerando os valores de referência estabelecidos pelo laboratório de análises clínicas do HUMAP.

\subsubsection{Avaliação física}

$\mathrm{Na}$ avaliação física, foram considerados os seguintes aspectos como sinais de depleção: Bola de bichart, sinal de asa quebrada, redução da musculatura temporal, presença de ossos proeminentes, edema, pele ressecada, desidratação, redução do tecido adiposo, redução da massa muscular, mucosa hipocoradas (CRUZ; ACUÑA, 2004).

\subsubsection{Sintomas gastrointestinais}

Foram avaliados os sintomas mais prevalentes nessa patologia como: disfagia, náuseas, vômitos, perda de apetite, constipação, diarreia e dor abdominal. Esses dados de grande relevância, quando se tem o interesse em perceber aspectos de baixa ingestão alimentar e desnutrição (BRITO; DREYER, 2003).

\subsubsection{Antropometria}

A antropometria foi realizada mensurando peso e estatura aos indivíduos que deambulavam, nestes o peso foi obtido por meio de balança digital portátil Relaxmedic ${ }^{\circledR}$ e a altura foi aferida por meio de estadiômetro Nutrivida ${ }^{\circledR}$. Em pacientes edemaciados foi realizado desconto subjetivo do edema, graduado conforme o protocolo de Duarte e Castellani (2002). A circunferência do braço (CB) foi analisada utilizando fita métrica inelástica de fibra de vidro.

Para os pacientes restritos ao leito, o peso e a estatura foram obtidos pela fórmula de Chumlea, Roche e Steinbaugh (1985). A CB foi mensurada 
com o indivíduo deitado, olhando para cima com cabeça apoiada no travesseiro. A circunferência foi mensurada no ponto médio do braço, que se posicionará estendido sobre a cama com a palma da mão voltada para cima. O indicador antropométrico utilizado foi o Índice de Massa Corpórea (IMC), sendo o resultado obtido classificado conforme Organização Mundial da Saúde (OMS, 1997).

\subsubsection{Composição corporal}

Para a avaliação da composição corporal, foi utilizada a adequação da circunferência do Braço (\% adequação de CB). A medida da CB obtida foi comparada ao padrão de referência e classificação segundo Frisancho (1990). O Peso ideal foi classificado segundo Frisancho (1984), considerando esse dado de relevância para averiguar qual seria o melhor peso para o paciente, sendo, em seguida, estabelecida a relação utilizando a adequação de peso.

\subsubsection{Diagnóstico nutricional}

O diagnóstico nutricional foi definido através da combinação de parâmetros subjetivos da avaliação nutricional (história clínica e exame físico) e objetivos (antropometria e exames bioquímicos).

\subsection{Análise estatística}

Os dados obtidos foram analisados através da planilha Microsoft Excel $^{\circledR}$, e a estatística ocorreu através software SPSS (Statistical Package for the Social Sciences) versão 18.0 através de uma análise descritiva dos resultados. As variáveis estudadas foram testadas em relação à sua normalidade para escolha do(s) teste(s) estatístico(s) mais apropriado(s), considerando um nível de $5 \%$ de significância $(p<0,05)$. 


\section{RESULTADOS E DISCUSSÃO}

\subsection{Aspectos sociodemográficos dos pacientes hospitalizados com HIV/Aids}

Aos aspectos sociodemográficos que caracterizaram a população pesquisada, referem-se 40 indivíduos participantes. Destes, 82,5\% ( $n=33)$ eram homens, com uma relação de 4,7 homens para cada mulher, e idades de 29 a 49 anos em 67,5\% dos indivíduos.

No Brasil, de 2007 até junho de 2016, foram notificados, no Sistema de Informação de Agravos de Notificação (Sinan), 136.945 casos de infecção pelo HIV. O sexo masculino apresentou maior incidência com uma relação de 2,4 homens a cada mulher infectada. Nesse estudo, ainda se observou que a maioria dos casos de infecções pelo vírus HIV encontra-se nas faixas de 20 a 34 anos em 52,3\% dos casos (BRASIL, 2016). Dados estes, semeIhantes ao presente estudo que apresentou prevalência de indivíduos do sexo masculino, adultos (20 a 49 anos) de ambos os sexos.

O estudo de Reis et al. (2011), realizado com indivíduos HIV em ambulatórios especializados de um município do interior do Estado de São Paulo, com o objetivo avaliar a qualidade de vida e sua relação com os fatores sociodemográficos e os referentes à sexualidade, apresentou um perfil também próximo ao presente estudo, com predomínio do sexo masculino e faixa etária dos 20 aos 39 anos (54\%).

Segundo Correia, Cornélio e Almeida (2013), a contaminação predominante ao público masculino se dá pela desvalorização do autocuidado e pouca preocupação com a saúde. O homem tende a carregar o estigma de ser o sexo forte e viril. No entanto, para ocorrer a mudança desse pensamento, é necessária a sensibilização desse grupo, separando a fragilidade da feminilidade.

Outro aspecto preocupante é de os jovens apresentarem a faixa etária mais prevalente. Isto pode indicar a possibilidade de esta infecção ter ocorrido ainda na adolescência, reforçando uma maior atenção e prioridade no cuidado a esse grupo.

Dos indivíduos desse estudo, 52,5\% apresentaram baixa ou nenhuma escolaridade. Diante desse panorama, infere-se que o baixo nível escolar pode refletir diretamente na eficiência da adesão ao tratamento. 
O baixo nível de escolaridade detectado é um critério de avaliação importante quando se considera que a conscientização sobre a enfermidade requer um nível satisfatório de escolaridade. Uma possível explicação é que, quando se possui "mais anos de estudo", o indivíduo têm maior acesso à informação e prevenção, tornando-se consciente sobre os benefícios do tratamento na evolução clínica da doença (PIERI; LAURENTI, 2012).

Resultado próximo a este estudo foi a pesquisa de Almeida et al. (2011) realizada no município de Campo Grande, MS, com indivíduos HIV/Aids, na qual investigaram os fatores intervenientes na adesão ao tratamento. Constatando que 55\% dos entrevistados possuíam apenas o ensino fundamental incompleto, e a faixa etária obtida apresentava $45 \%$ dos portadores de HIV/Aids com idade entre 30 e 40 anos.

Vale salientar que esses dados são preocupantes uma vez que existe a apresentação de uma população sexualmente ativa e de baixo nível escolar, subentendendo-se que possuem baixo conhecimento sobre prevenção e transmissão da doença, podendo contribuir para o aumento da incidência e mortalidade.

Além do precário acesso à informação que esse público possa ter, outro aspecto é o acesso e uso de drogas e álcool. Na presente pesquisa, os indivíduos predominantemente alegaram não ser etilista (75\%), não ser tabagista (72,5\%) e não utilizar drogas ilícitas (85\%).

No entanto é evidente que a relação entre drogas e relação sexual facilita a exposição das pessoas à infecção pelo vírus da AIDS frente ao efeito modulador dessas substâncias sobre comportamento de pessoas, e estas frente a práticas sexuais (BASTOS; BERTONI; HACKER, 2008). 


\subsection{Análise dos aspectos clínicos dos pacientes hospitalizados com HIV/Aids}

Tabela 1 - Aspectos clínicos dos pacientes HIV/Aids hospitalizados no PAM e na clínica de DIP de um hospital universitário em Campo Grande, MS, 2016

\section{Variáveis}

Diagnóstico principal

SIDA/Aids

HIV

$\mathrm{CD} 4 / \mathrm{mm}^{3}$

$<200$

$200-350$

351-500

$>500$

CV- Carga viral $/ \mathrm{mm}^{3}$

100.000-1.000.000

10.000-99.999

$<10.000$

Indetectável
29

11

26

6

3

5

14

35

4

10

12

30

10

25
15

7,5

12,5

Tempo de diagnóstico de HIV

Abertura de caso

13

32,5

Menos de 1 ano

De 1-5 anos

5

12,5

$>5$ anos

15

37,5

Tratamento Regular com a TARV

Sim

12

30

Não

Motivo pelo não tratamento $(n=28)$ *

Efeito colateral

$\begin{array}{cc}1 & 3,6 \\ 6 & 21,4 \\ 5 & 17,9 \\ 3 & 10,7 \\ 13 & 46,4\end{array}$

Desistência por depressão

Esquecia de tomar

Nao soube relatar 46,4 


\begin{tabular}{lcc}
\hline \multicolumn{1}{c}{ Variáveis } & $\mathbf{n}$ & \% \\
\hline Comorbidades & 3 & \\
Tuberculose & 1 & 7,5 \\
Meningoencefalite & 2 & 2,5 \\
Hepatite B & 1 & 5 \\
Sífilis & 1 & 2,5 \\
Pneumonia & 11 & 2,5 \\
Neurotoxoplasmose & 6 & 27,5 \\
Pneumosistose & 1 & 15,0 \\
Criptococose & 1 & 2,5 \\
Meningite Viral & 1 & 2,5 \\
GECA & 1 & 2,5 \\
Toxoplasmose & 4 & 2,5 \\
Neurocriptococose & 4 & 10,0 \\
Neurotuberculose & 3 & 10,0 \\
Leishmaniose & 3,5 \\
\hline
\end{tabular}

*Motivo pelo não tratamento: refere-se apenas aos indivíduos que relataram não realizar tratamento regular com a TARV (28 indivíduos, dos 40 estudados).

Na Tabela 1, verifica-se que 72,5\% dos indivíduos com HIV foram diagnosticados com SIDA/ Aids. Vale ressaltar que predominantemente os valores de CD4 apresentaram-se baixos e carga viral em altos índices.

Dos pesquisados, $50 \%$ destes sabiam do diagnóstico de HIV há pelo menos um ano, e 53,6\% dos indivíduos (que não eram abertura de caso) desprezavam o tratamento regular com a terapia antiretroviral (TARV). Destes, $21,4 \%$ relataram não realizar o tratamento regular por depressão, apresentando uma relação ruim entre a negligência ao tratamento e consequentemente baixos indicadores imunitários, desencadeando o aparecimento das doenças oportunistas, como as descritas na Tabela 1.

Nesse sentido, o grande desafio com o indivíduo com HIV/Aids refere-se ao nível de adesão ao tratamento para que este se faça eficaz. É sabido que os pacientes que não realizam o tratamento antirretroviral ou que realizam de forma interrupta, frequentemente apresentam infecções oportunistas e neoplasias. Dentre estas, destacam-se: pneumocistose, neurotoxoplasmose, tuberculose pulmonar atípica ou disseminada, meningite 
criptocócica e retinite por citomegalovirus, causando a progressão da doença e debilitando cada vez mais o indivíduo (BRASIL, 2013).

Pôde-se observar que os 40 indivíduos apresentaram comorbidades associadas à doença base. Ao investigar as comorbidades prevalentes no público participante, observou-se neurotoxoplasmose e a pneumosistose, apresentando $27,5 \%$ e $15 \%$ dos casos respectivamente, como as mais frequentes, seguidas pela neurocriptococose e neurotuberculose.

Silva et al. (2015) analisaram 20 pacientes, com idade entre 23 e 58 anos. Todos os pacientes avaliados apresentaram alguma doença em decorrência da imunossupressão resultante do HIV. Neste estudo, 85 \% não utilizavam TARV de forma regular, estabelecendo uma correlação da baixa adesão da TARV com o aparecimento de doenças oportunistas, especialmente como tuberculose, na forma clássica, ou alterações no sistema neurológico, decorrentes de Toxoplasma gondii, como neurotoxoplasmose, podendo desencadear declínio do nível de consciência e convulsões.

No estudo de Furine et al. (2010), que avaliaram prontuários de pacientes portadores do HIV/Aids no estado de São Paulo, para descrição de características epidemiológicas e correlação de prováveis infecções ao perfil imunológico, encontraram a toxoplasmose encefálica $(34,1 \%)$, a retinite por citomegalovírus (32,89\%) e a tuberculose $(15,79 \%)$ como as infecções oportunistas que ocorreram com maior frequência.

\subsection{Análise dos aspectos laboratoriais e bioquímicos dos pacientes hospitalizados com HIV/Aids}

A Tabela 2 apresenta as características laboratoriais que podem ser associados com estado de depleção nutricional. São dados coletados no início, ou seja, primeira avaliação e fim, como sendo a última avaliação antes do desfecho clínico do paciente. 
Tabela 2 - Aspectos Laboratoriais e Bioquímicos dos pacientes HIV/Aids hospitalizados no PAM e na clínica de DIP de um hospital universitário em Campo Grande, MS, 2016

Variáveis

Depleção Grave

Depleção Moderada

Depleção Leve

Adequado

\section{PT - Proteínas Totais}

Menor que a referência

Adequado

Maior que a referência

\section{Albumina}

Depleção Grave

Depleção Moderada

Depleção Leve

Adequado

\section{Creatinina}

Menor que a referência

Adequado

Maior que a referência

\section{Ureia}

Menor que a referência

Adequado

Maior que a referência

\section{PCR - Proteína C Reativa}

Menor que a referência Adequado

Maior que a referência

$\begin{array}{cccc}19 & 47,5 & 24 & 60 \\ 8 & 20 & 6 & 15 \\ 6 & 15 & 7 & 17,5 \\ 7 & 17,5 & 3 & 7,5\end{array}$

$\begin{array}{cccc}15 & 37,5 & 13 & 32,5 \\ 18 & 45 & 22 & 55 \\ 7 & 17,5 & 5 & 12,5\end{array}$

$\begin{array}{cccc}8 & 20 & 7 & 17,5 \\ 14 & 35 & 11 & 27,5 \\ 13 & 32,5 & 13 & 32,5 \\ 5 & 12,5 & 9 & 22,5\end{array}$

$\begin{array}{cccc}4 & 10 & 2 & 5 \\ 31 & 77,5 & 30 & 75 \\ 5 & 12,5 & 8 & 20\end{array}$

$\begin{array}{cccc}0 & 0 & 1 & 2,5 \\ 34 & 85 & 32 & 80 \\ 6 & 15 & 7 & 17,5\end{array}$

Linfócitos e leucócitos periféricos são considerados marcadores nutricionais, quando utilizados para o cálculo da Contagem Total de Linfócitos (CTL) e medem as reservas imunológicas momentâneas. Os resultados referentes a CTL desta pesquisa, demonstram depleção durante todo o 
período de internação dos indivíduos. Quando comparado ao padrão de adequação, esse dado apresentou piora dos seus parâmetros do início ao fim da avaliação, apresentando depleção em 82,5\% dos indivíduos para $92,5 \%$ respectivamente.

A CTL indica as condições de defesa celular do organismo. Esse dado sofre influência direta do estado nutricional e, portanto, é considerado um parâmetro nutricional para determinar a competência imunológica. No entanto a CTL como indicador nutricional é limitada em casos de infecções, síndrome da imunodeficiência adquirida, câncer terminal, doenças agudas e lúpus (DIESTEL, TORRES, 2007; OLIVEIRA; ROCHA; SILVA, 2008).

Com relação às proteínas totais, verificou-se que, na avaliação inicial, houve uma distribuição equilibrada entre os padrões de adequação e inadequação (menor e maior). Porém, independente disto, 45\% apresentaram-se adequados. Ao decorrer da internação, no último exame coletado, a maioria dos indivíduos (55\%) apresentaram esse dado adequado.

As proteínas são fundamentais nos processos fisiológicos. A análise das proporções de suas frações tem considerável valor na abordagem de distúrbios agudos e crônicos. A desnutrição e os desvios nutricionais ocasionam a redução da imunidade, aumentando, portanto, o risco de infecções. A redução de proteína sérica é estreitamente relacionada com depleção nutricional (FONTOURA et al., 2006).

Valores referentes à albumina quando comparados início e fim, apresentaram algum grau de depleção, porém houve uma melhora no decorrer da internação desse parâmetro. Inicialmente $87,5 \%$ dos pacientes apresentaram hipoalbuminemia, sendo que $55 \%$ destes, moderada a grave. Ao final da avaliação, esses valores reduziram para 77,5\% hipoalbuminêmicos.

Segundo Fontoura et al. (2006), a albumina sérica é um indicador bioquímico de desnutrição muito utilizado e é considerado como um preditor de mortalidade e morbidade. Em pacientes hospitalizados, deve-se monitorar cuidadosamente as concentrações séricas de proteínas de síntese hepática, como a albumina, uma vez que pode ser afetada pelo estado de hidratação, infecção e outras causas de inflamação (CELIK et al., 2011).

Nota-se, nesta pesquisa, que ureia e creatinina não apresentaram discrepância, quando analisadas no início e fim da coleta dos dados, 75\% dos 
indivíduos apresentaram valores de creatinina adequados e ureia $80 \%$, conforme a referência estabelecida pelo laboratório da instituição pesquisada.

Observa-se que, durante todo o período de internação, a dosagem de PCR permaneceu elevada, inicialmente em $85 \%$ dos indivíduos e, ao fim da avaliação, em $82,5 \%$. Isso indica que a maior parte dos pacientes estudados apresentou desde a admissão hospitalar presença de inflamação e/ou infecção e que até ao desfecho clínico esse parâmetro ainda mantinha-se presente.

A PCR é um reagente inflamatório que deve ser considerado quando se pretende realizar um diagnóstico nutricional, levando em conta as informações laboratoriais e bioquímicas, como albumina, PT e CTL, que são sensíveis e afetadas em processos inflamatórios e infecciosos e não devem ser exclusivamente consideradas, para se realizar um diagnóstico nutricional nesses casos. Por isso, vale ressaltar a importância de se realizar uma avaliação nutricional completa e considerar todos os aspectos norteadores que caracterizam e constituem um diagnóstico nutricional, olhando o indivíduo como um todo.

\subsection{Análise dos aspectos nutricionais dos pacientes hospitalizados com HIV/Aids}

Na tabela 3 estão dispostos dados sobre aspectos nutricionais dos pacientes HIV/aids hospitalizados. 
Tabela 3 - Aspectos nutricionais dos pacientes HIV/Aids hospitalizados no PAM e na clínica de DIP de um hospital universitário em Campo Grande, MS, 2016

\begin{tabular}{lllll}
\multirow{2}{*}{ Variáveis } & \multicolumn{2}{c}{ Início } & \multicolumn{2}{c}{ Fim } \\
\cline { 2 - 5 } & $\mathrm{n}$ & $\%$ & $\mathrm{n}$ & $\%$
\end{tabular}

\section{ANTROPOMETRIA}

IMC- Índice de Massa Corporal

Desnutrição Grave

Desnutrição Moderada

Desnutrição Leve

Eutrófico

$\geq$ Sobrepeso

\section{Adequação do Peso}

Desnutrição Grave

Desnutrição Moderada

Desnutrição Leve

Eutrófico

$\geq$ Sobrepeso

\section{Adequação CB}

Desnutrição Grave

Desnutrição Moderada

Desnutrição Leve

Eutrófico

$\geq$ Sobrepeso

\section{Via de Administração da Dieta}

Oral

Enteral

Mista

\section{Terapia Nutricional- Caloria}

Normocalórica

Hipercalórica

\section{Terapia Nutricional- Proteína}

Normoproteica

Hiperproteica

\section{Exame Físico - Presença de Alteração}

Ossos proeminentes

Sinal de Asa Quebrada

Redução da bola de Bichat

Edema

Redução das temporas

Pele Ressecada

$\begin{array}{cccc}8 & 20 & 4 & 10 \\ 3 & 7,5 & 4 & 10 \\ 6 & 15 & 14 & 35 \\ 19 & 47,5 & 16 & 40 \\ 4 & 10 & 2 & 5\end{array}$

11

27,5

12

30

15

37,5

15

37,5

6

15

17,5

17,5

15

2,5

6

0

\section{0} 5

$\begin{array}{cccc}8 & 20 & 10 & 25 \\ 18 & 45 & 18 & 45 \\ 10 & 25 & 6 & 15 \\ 4 & 10 & 6 & 15 \\ 0 & 0 & 0 & 0\end{array}$

$\begin{array}{cccc}32 & 80 & 24 & 60 \\ 8 & 20 & 11 & 27,5 \\ 0 & 0 & 5 & 12,5\end{array}$

$\begin{array}{llll}21 & 52,5 & 18 & 45 \\ 19 & 47,5 & 22 & 55\end{array}$

$\begin{array}{llll}19 & 47,5 & 19 & 47,5 \\ 21 & 52,5 & 21 & 52,5\end{array}$




\begin{tabular}{lcccc}
\hline \multirow{2}{*}{ Variáveis } & \multicolumn{2}{c}{ Início } & \multicolumn{2}{c}{ Fim } \\
\cline { 2 - 5 } & $\mathbf{n}$ & $\mathbf{\%}$ & $\mathbf{n}$ & $\mathbf{\%}$ \\
\hline Desidratação & 7 & 17,5 & 8 & 20 \\
Redução do tecido adiposo & 11 & 27,5 & 12 & 30 \\
Redução da massa muscular & 22 & 55 & 26 & 65 \\
Mucosa Hipocorada & 9 & 22,5 & 8 & 20 \\
Sintomas Gastrointestinais & & & & \\
Disfagia & 1 & 2,5 & 0 & 0 \\
Náuseas & 9 & 22,5 & 5 & 12,5 \\
Vômitos & 14 & 35 & 0 & 0 \\
Perda de apetite & 13 & 32,5 & 5 & 12,5 \\
Constipação & 4 & 10 & 0 & 0 \\
Diarreia & 6 & 15 & 10 & 25 \\
Dor abdominal & 1 & 2,5 & 0 & 0 \\
Nenhum & 10 & 25 & 20 & 50 \\
Diagnóstico Nutricional & & & & \\
Desnutridos & 21 & 52,5 & 25 & 62,5 \\
Não desnutridos & 19 & 47,5 & 15 & 37,5 \\
\hline
\end{tabular}

* Nas variáveis "Exame Físico" e "Sintomas Gastrointestinais", valores referentes a n. indicam o número de indivíduos que apresentaram as características correspondentes, no entanto um mesmo indivíduo apresentou mais de uma característica.

Ao analisar-se os resultados referentes às características antropométricas, inicialmente, observou-se que o IMC de 42,5\% dos indivíduos apontaram algum grau de desnutrição e, ao final do acompanhamento, 55\% apresentavam-se desnutridos. Ao analisarmos a adequação de peso (relação entre peso atual e o ideal dos indivíduos), 80\% apresentaram-se desnutridos no início e, ao final, esse índice aumentou para 85\%. É interessante perceber que, no decorrer da internação, houve piora do estado nutricional dos indivíduos e, mesmo que o IMC apontasse desnutrição em pelo menos metade dos pesquisados, a adequação de peso demonstra que mesmo os indivíduos eutróficos apresentavam risco de desnutrição, uma vez que muitos estavam abaixo do peso comparado ao seu peso ideal.

Pesquisa similar foi realizada por Ferraz, Viriato e Moura (2013), a qual objetivou apresentar o diagnóstico nutricional de pacientes portadores de doenças infectocontagiosas, admitidos em um Instituto de Infectologia. Observou que o IMC teve uma prevalência de 47,4\% de magreza sendo quase metade $(n=29)$ com desnutrição em pior grau. 
A circunferência do braço, conforme mencionam Walsek, Zafonte e Bowers (1997), frequentemente evidencia déficit severo da reserva adiposa em relação ao padrão para o sexo e idade nos pacientes hospitalizados, representando a soma das áreas constituídas pelos tecidos ósseos, muscular e gorduroso do braço, e é considerada uma técnica simples, rápida e barata. Ao avaliar-se a CB no presente estudo, notou-se que $90 \%$ dos indivíduos apresentaram desnutrição, desses 65\% $(n=26)$ desnutrição moderada e grave, informação relevante quando se percebe que, ao fim do acompanhamento, esse índice ainda permaneceu elevado com 85\% dos indivíduos em desnutrição pela CB.

A terapia nutricional preferencialmente prescrita no presente estudo possui as seguintes características: a via de administração escolhida foi a via oral, do início ao fim do acompanhamento, representando 80\% e 60\% respectivamente.

Segundo Côrtes et al. (2003), a escolha da via de terapia nutricional é fundamental e decisiva, pois a nutrição, pode resultar numa melhor evolução da doença de base com maior sobrevida e menor ônus hospitalar, para tanto é necessário que a terapia nutricional possa ser ofertada.

Quanto à característica das dietas, nota-se que inicialmente a prescrição dietética foi caracterizada por dieta normocalórica e hiperproteica para $52,5 \%(n=21)$ das prescrições. Ao fim do acompanhamento, a oferta calórica passou a ser 55\% hipercalórica e manteve-se 52,5\% hiperproteica. Entende-se que houve uma mudança dietética nesse período conforme rotina de acompanhamento e prescrição da nutricionista do setor.

Segundo o Projeto Diretrizes de Terapia Nutricional na Síndrome da Imunodeficiência Adquirida (HIV/AIDS) (SOCIEDADE BRASILEIRA DE NUTRIÇÃO, PARENTERAL E ENTERAL [SBNEP]/ASSOCIAÇÃO BRASILEIRA DE NUTROLOGIA [ABRAN], 2011), recomenda-se que, na fase estável da doença, a necessidade proteica deve ser $1,2 \mathrm{~g} / \mathrm{kg}$ peso atual/dia. Porém, na fase aguda, a necessidade de proteínas aumenta para $1,5 \mathrm{~g} / \mathrm{kg}$ de peso atual/dia. Já a necessidade energética para paciente assintomático é de 30-35 kcal/kg/dia, em paciente sintomático com a doença propriamente dita, a necessidade é de $40 \mathrm{kcal} / \mathrm{kg} / \mathrm{dia}$. O suporte nutricional adequado contribui para redução da prevalência e magnitude da desnutrição, melhora 
o prognóstico clínico e ajuda a reduzir os custos do tratamento (GALLAGHERALLRED et al., 1996).

As avaliações subjetivas têm como base a interpretação semiológica dos sinais e sintomas clínicos (orogastrointestinais especialmente) e o exame físico do paciente como indicador nutricional. De acordo com Chan, McCowen e Blackburn (1999), o exame físico deve evidenciar sinais de deficiência de micronutrientes, estado de hidratação, além do exame físico de compartimentos gordurosos e musculares, os quais indicam a gravidade da desnutrição proteico/calórica dos indivíduos.

No presente estudo, as alterações mais prevalentes, observadas ao exame físico, foram ossos proeminentes, redução de massa muscular corporal e sinais de desnutrição em face (redução da bola gordurosa de Bichat e redução das têmporas), apresentando durante o acompanhamento (início ao fim), um incremento do seu percentual.

Quanto aos sintomas gastrointestinais mais relatados, foram prevalentes náuseas, vômitos e perda de apetite. No entanto notou-se que, ao decorrer do período de internação e ao fim do atendimento, os valores referentes sofreram redução, ou seja, os indivíduos obtiveram melhoras dessas afecções gastrointestinais. Vale ressaltar que a diarreia apresentou acréscimo quando comparada no inicio e fim da avaliação.

É sabido que a ingestão alimentar reduzida, e consequente perda de peso, pode estar associada a uma série de fatores como: pouca disponibilidade de alimentos, anorexia, fadiga, náuseas e vômitos (POLACOW, 2004). Nos indivíduos com HIV/Sida, a principal razão para que ocorra um balanço energético negativo é a ingestão energética reduzida, consequente da perda de apetite, a qual se deve ao processo metabólico, que o reduz em muitas infecções sistêmicas e intestinais e ao uso de alguns fármacos antirretrovirais (HSU et al., 2005).

Segundo Teixeira, Caruso e Soriano (2006), apesar da importância da adequada ingestão de nutrientes e energia, os pacientes que se encontram críticos hospitalizados frequentemente recebem um valor energético inferior às suas necessidades. Fato que frequentemente ocorre por fatores que impedem o adequado aporte nutricional relacionados à intolerância da dieta, como vômitos, diarreia, resíduo gástrico, distensão abdominal, dentre outros. 
Considerando todos os aspectos norteadores da avalição nutricional e aqueles previamente apresentados nas tabelas anteriores, foi realizado o diagnóstico nutricional com os pacientes. Ao início do acompanhamento, $52,5 \%$ ( $n=21$ ) foram diagnosticados como desnutridos e, na última avaliação, esse índice aumentou para 62,5\%. Percebe-se que ao menos metade dos pacientes já foram hospitalizados desnutridos. Essa informação é muito relevante, pois recuperar o peso de um indivíduo hospitalizado é desafiador frente a todos os aspectos clínicos e estado catabólico, ao qual está exposto. Em situações de desnutrição prévia à internação, a recuperação do estado nutricional é ainda mais dificultada.

Diante das comorbidades e suas consequentes sintomatologias, esses pacientes apresentam-se em ampla e complexa resposta metabólica. O hipermetabolismo, a leucopenia, a redução da defesa imunológica, o aparecimento de diversas infecções, a proteólise muscular e diminuição da síntese de albumina desencadeiam a exacerbação do consumo corporal, anorexia e caquexia, tornando o estado nutricional desses pacientes comprometidos (GRAMLICH; MASCIOLI, 1995). A desnutrição proteico-energética de origem multifatorial é consequência marcante da doença e ocorre frequentemente (SBNEP/ABRAN, 2011).

Diante desse exposto, entende-se que, se a avaliação e o acompanhamento nutricional não forem feitos no momento e durante a internação hospitalar, os pacientes correm o risco de se desnutrir ao longo do tempo, e os que já estavam desnutridos tendem a ter seu grau de desnutrição agravado durante a hospitalização (BARBOSA et al, 2002).

\section{CONSIDERAÇÕES FINAIS}

Os resultados desta pesquisa apontam que não houve diferenças significativas quando associamos diagnóstico, tempo e desfecho clínico dos indivíduos acompanhados. No entanto observou-se que a situação de desnutrição é presente no ambiente hospitalar e está relacionada fortemente à situação nutricional previamente encontrada na admissão desses pacientes na instituição de cuidado. A pesquisa decorre da dificuldade de recuperar e/ou manter o estado nutricional desses indivíduos, e muitos apresentam piora deste durante a hospitalização. A desnutrição é associada 
a um prognóstico ruim; dessa forma, o acompanhamento, a avaliação e a intervenção nutricional precoce poderão ser decisivas promovendo melhor evolução e desfecho clínico.

\section{REFERÊNCIAS}

ALMEIDA, E. L.; ARAUJO, G. B. S.; SANTOS, V. A.; BUSTORFF, L. A. C. V.; PEREIRA, A. V. L.; DIAS, M. D. Adesão dos portadores do HIV/Aids ao tratamento: fatores intervenientes. Revista Mineira de Enfermagem, Belo Horizonte, MG, v. 15, n. 2, p. 208-16, abr./jun. 2011.

BARBOSA, E.; COLOMBO, P. P. F.; NOGUEIRA, T. L.; FREITAS, S. F. T. Perfil nutricional de crianças desnutridas internadas - uma realidade do Hospital Infantil Joana de Gusmão. Revista Brasileira de Nutrição Clínica, São Paulo, v. 17, n. 4, p. 137-42, 2002.

BASTOS, F. I.; BERTONI, N.; HACKER, M. A. Consumo de álcool e drogas: principais achados de pesquisa de âmbito nacional. Revista de Saúde Pública, São Paulo, v. 42, suplemento 1, p.109-17, jun. 2008.

CHAN, S.; MCCOWEN, K.C.; BLACKBURN, G. L. Nutrition management in ICU. Chest, v. 115, n. 5 (suplemento), p. 145S-8S, maio 1999.

BRASIL. Ministério da Saúde. Secretaria de Vigilância em Saúde. Boletim epidemiológico AIDS e DST. Brasília: Ministério da Saúde, 2016.

. Ministério da Saúde. Secretaria de Vigilância em Saúde. Departamento de DST, Aids e Hepatites Virais. Protocolo clínico e Diretrizes terapêuticas para adultos vivendo com HIV/AIDS. Brasília: Ministério da Saúde, 2013.

BRITO, S.; DREYER, E. Terapia nutricional: condutas do nutricionista. Hospital das Clínicas, 2003. Disponível em: <http://www.hc.unicamp.br/servicos/emtn/ manual_nutricionista_2004-11-02.pdf>.

CELIK, G.; OC, B.; KARA, I.; YILMAZ, M.; YUCEAKTAS, A.; APILIOGULLARI, S. Comparison of nutritional parameters among adult and elderly hemodialysis patients. International Journal of Medical Sciences, v. 8, n. 7, p. 628-34, out. 2011.

CHUMLEA, W. C.; ROCHE, A. F.; STEINBAUGH, M. L. Estimating sature from knee height for persons 60 to 90 years of age. Journal of the American Geriatrics Society, v. 33, n. 2, p. 116-20, fev. 1985.

CORREIA, P. F.; CORNÉLIO, R. P.; ALMEIDA, J. S. S. Saúde do homem: caracterização dos portadores de HIV-AIDS em Sergipe. Cadernos de Graduação - Ciências Biológicas e da Saúde, Aracaju, SE, v. 1, n. 17, p. 13-26, out. 2013.

CÔRTES, J. F. F.; FERNANDES, S. L.; NOGUEIRA-MADURO, I. P. N.; BASILE-FILHO, A.; SUEN, V. M. M.; SANTOS, J. E.; VANNUCHI, H.; MARCHINI, J. S. Terapia nutricional 
no paciente criticamente enfermo. Medicina, Ribeirão Preto, SP, n. 36, p. 394-8, abr./dez. 2003.

CRUZ, T.; ACUÑA, K. Avaliação do estado nutricional de adultos e idosos e situação nutricional da população brasileira. Arquivos Brasileiros de Endocrinologia \& Metabologia, São Paulo, v. 48, n. 3, p. 345-61, jun. 2004.

DIESTEL, C. F.; TORRES, M. R. S. G. Semiologia nutricional no pré-operatório. In: DUARTE, A. C. G. (Org.). Avaliação nutricional: aspectos clínicos e laboratoriais. São Paulo: Atheneu, 2007. p. 243-8.

DUARTE, A. C.; CASTELLANI, F. R. Semiologia nutricional. Rio de Janeiro: Axcel Books do Brasil, 2002.

FERRAZ, L.F.; VIRIATO, A.; MOURA, A. Análise do diagnóstico nutricional de pacientes em assistência hospitalar de infectologia. O Mundo da Saúde, São Paulo, v. 37, n. 3, p. 253-8, 2013.

FONTOURA, C. S. M.; CRUZ, D. O.; LONDERO, L. G.; VIEIRA, R. M. Avaliação nutricional de paciente crítico. Revista Brasileira de Terapia Intensiva, v. 18, n. 3, p. 298-306, ju./set. 2006.

FRISANCHO, A. R. Anthropometric standards of the assessment of growth and nutritional status. Ann Arbor, MI: University of Michigan Press, 1990.

. New standards of weight and body composition by frame size and height for assessment of nutritional status of adults and the elderly. The American Journal Clinical Nutrition, v. 40, n. 4, p. 808-19, out. 1984.

FURINI, A. A. C.; SCHIESARI JUNIOR, A.; SOUZA, M. S. R.; HELENA, C. C.; ROSSIT, A. R. B.; MACHADO, R. L. D. Perfil das coinfecções em indivíduos soropositivos para o HIV1 atendidos em um Hospital Escola do Noroeste Paulista, Brasil: dados preliminares. Revista Panamericana de Infectologia, v. 13, n. 3, p. 39-42, 2010. Disponível em: <http://www.revistaapi.com/wp-content/uploads/2014/03/API_03_10_G.pdf >.

GALLAGHER-ALLRED, C. R.; VOSS, A. C.; FINN, S. C.; MCCAMISH, M. A. Malnutrition and clinical outcomes: the case for medical nutrition therapy. Journal of the American Dietetic Association, v. 96, n. 4, p. 361-9, abr. 1996.

GARCIA, R. W. D; QUINTAES, K. D.; MERHI, V. A. Nutrição e Aids. Revista Ciências Médicas, Campinas, SP, v. 9, n. 2, p. 52-73, 2000.

GRAMLICH, L. M.; MASCIOLI, E. A. Nutrition and HIV infection. The Journal of Nutritional Biochemistry, v. 6, n. 1, p. 2-11, jan. 1995.

HSU, J.; PENCHARZ, P. B.; MACALLAN, D.; TOMKINS, A. Macronutrients and HIV/AIDS: a review of current evidence. Durban, South Africa: World Health Organization, 2005. 
OLIVEIRA, L. M. L.; ROCHA, A. P. C.; SILVA, J. M. A. Avaliação nutricional em pacientes hospitalizados: uma responsabilidade interdisciplinar. Revista Saber Científico, Porto Velho, RO, v. 1, n. 1, p. 240-52, jan./jun. 2008.

ORGANIZAÇÃO MUNDIAL DA SAÚDE (OMS). CID-10 Classificação Estatística Internacional de Doenças e Problemas Relacionados à Saúde. 10. rev. São Paulo: Universidade de São Paulo, 1997. v. 2.

PIERI, F. M.; LAURENTI, R. HIV/AIDS: perfil epidemiológico de adultos internados em hospital universitário. Ciência, Cuidado e Saúde, Maringá, PR, v. 11 (suplemento), p. 144-52, 2012.

POLACOW, V. O.; SCAGLIUSI, F. B.; FURTADO, L. S. M.; CARRÉ, M. L.; PEREIRA, G. M.; AVILEIS, C. G. Alterações do estado nutricional e dietoterapia na infecção por HIV. Revista Brasileira de Nutrição Clínica, v. 19, n. 2, p. 79-85, abr./jun. 2004.

REIS, R. K.; SANTOS, C. B.; DANTAS, R. A. S.; GIR, E. Qualidade de vida, aspectos sociodemográficos e de sexualidade de pessoas vivendo com HIV/AIDS. Revista Texto Contexto Enfermagem, Florianópolis, SC, v. 20, n. 9, p. 565-75, jul./set. 2011.

SILVA, A. A. A.; LIMA, D. A.; MATOS, A. R.; OLIVEIRA, L. M. L.; SANTOS, I. H. V. S. Prevalência de má nutrição e doenças oportunistas em pacientes HIV/Aids internados em um hospital de referência de Porto Velho- Rondônia. Saber Científico, Porto Velho, RO, v. 4, n. 1, p. 58-64, jan./jun. 2015. Disponível em: <http://revista. saolucas.edu.br/index.php/resc/article/view/529/PDF>.

SOCIEDADE BRASILEIRA DE NUTRIÇÃO, PARENTERAL E ENTERAL (SBNEP)/ ASSOCIAÇÃO BRASILEIRA DE NUTROLOGIA (ABRAN). Terapia Nutricional na Síndrome da Imunodeficiência Adquirida (HIV/AIDS). Projeto Diretrizes, 2011.

TEIXEIRA, A. C. C.; CARUSO, L.; SORIANO, F. G. Terapia nutricional enteral em Unidade de Terapia Intensiva: infusão versus necessidades. Revista Brasileira de Terapia Intensiva, São Paulo, v. 18, n. 4, p. 331-7, out./dez. 2006.

WALSEK, C.; ZAFONTE, M.; BOWERS, J. M. Nutritional issues and HIV/AIDS: assessment and treatment strategies. Journal of Association Nurs AIDS Care, v. 8, n. 6, p. 71-80, nov./dez. 1997. 
